\title{
Indications, Outcome and Complications of Non-Invasive Positive Pressure Ventilation in Acute Respiratory Failure
}

\author{
Gosavi Rakhi A ${ }^{1}$, Kapse Vijaykumar $\mathbf{R}^{2^{\star}}$, Mhaisekar Dilip $\mathbf{G}^{2}$, Fazlullah Hashmi Syed ${ }^{2}$ and Luniya Anandkumar Babulal ${ }^{3}$ \\ ${ }^{1}$ Department of Pulmonary Medicine, BJ Medical College, Pune, Maharashtra, India \\ ${ }^{2}$ Department of Pulmonary Medicine, Dr. Shankarrao Chavhan Govt. Medical College, Nanded, Maharashtra, India \\ ${ }^{3}$ Department of Pulmonary Medicine, Smt. Kashibai Navale Medical College, Pune, Maharashtra, India
}

\begin{abstract}
Background: The use of noninvasive positive pressure ventilation (NIPPV) in treating of respiratory failure with diverse etiology is now widely studied. The recent increase in the use of NIPPV in the critical care units has been motivated by the desire to minimize complications of invasive ventilation. The present study was conducted to study the indications, outcome and complications of NIPPV in acute respiratory failure patients.

Material and Methods: In this prospective observational study, a total 110 adult patients of respiratory failure and impending respiratory failure due to various diseases attending a tertiary care centre and admitted in intensive respiratory care unit were studied for outcome and complications of NIPPV utilization.

Results: The most common indication of NIPPV was exacerbation of COPD 37 (33.63\%) followed by post extubation $30(27.27 \%)$, asthma $14(12.72 \%)$, ARDS $9(8.18 \%)$ and pneumonia $10(9.09 \%)$. NIPPV was effective in $88(80 \%)$ and non-effective in $22(20 \%)$. There was significant improvement which also persisted after successful weaning. Common complications observed were dry mouth in 60 (54.54\%) patients, facial injury in $21(19.09 \%)$ patients.

Discussion: NIPPV can be utilized as an effective modality in the management of ARF due to diverse etiologies. NIPPV was associated with a reduced need for invasive mechanical ventilation and significant outcome and minor complications.
\end{abstract}

Keywords: Non-invasive positive pressure ventilation; Acute respiratory failure; Outcome; Complications

\section{Introduction}

Noninvasive positive pressure ventilation (NIPPV) is defined as technique of augmenting alveolar ventilation without introducing endotracheal tube, thereby avoiding complication due to endotracheal intubation.

In spite of known impending severe complications, for many years, patients who developed respiratory failure had to be put on invasive mechanical ventilation (MV). Recently, numerous randomized controlled trials have been carried out on use of non-invasive ventilation (NIV) for patients with respiratory failure of varied etiology, such as, acute exacerbation of chronic obstructive pulmonary disease (COPD) [1,2], acute cardiogenic pulmonary oedema [3], hypoxaemic respiratory failure [4] and as an adjunct to weaning patients $[5,6]$. Nowadays, physicians have started to use NIV in patients with respiratory failure as much as possible instead of mechanical ventilation to avoid its complications.

The application of NIPPV in the management of patients with ARF is not associated with a $100 \%$ success rate. The failure rates of NIPPV can range from $5 \%$ to $50 \%$ in different studies depending on the etiology and severity of ARF [7-10]. Failure to identify the patients who are likely to fail NIPPV can cause inappropriate delay in intubation; this can lead to clinical deterioration and increased morbidity and mortality [8]. In many patients, application of NIV is non effective and eventually endotracheal intubation and invasive mechanical ventilation is required. Also, some patients get benefitted initially but will then deteriorate and require intubation. Thus, it becomes important to use the NIPPV in indicated cases only. Thus, the present study was conducted to study the indications, outcome and complications of NIPPV in acute respiratory failure patients.

\section{Material and Methods}

After approval from the institutional ethical committee this prospective observational study carried out in a total 110 adult patients of respiratory failure and impending respiratory failure due to various diseases (COPD, bronchial asthma, bronchiectasis, ARDS, pneumonia, pulmonary oedema, ILD) and post extubation who satisfied all the inclusion criteria attending a tertiary care centre and admitted in intensive respiratory care unit (IRCU) were studied from January 2013 to August 2014 over a period of 18 months.

\section{Inclusion criteria}

- Age more than 13 years.

- Patients with acute and impending respiratory failure with normal conscious level with able to maintain airway and mild to moderate hypoxemia.

- Patients on invasive mechanical ventilator for different etiologies who met weaning criteria were extubated early and included in study for immediate application of NIPPV.

*Corresponding author: Kapse Vijaykumar R, Department of Pulmonary Medicine, Dr. Shankarrao Chavhan Govt. Medical College, Nanded, Maharashtra India, Tel: 9881825252; E-mail: pravin1702@gmail.com

Received August 02, 2017; Accepted October 13, 2017; Published October 20 2017

Citation: Gosavi Rakhi A, Kapse Vijaykumar R, Mhaisekar Dilip G, Hashmi Syed F, Anandkumar Babulal L (2017) Indications, Outcome and Complications of NonInvasive Positive Pressure Ventilation in Acute Respiratory Failure. J Pulm Respir Med 7: 424. doi: 10.4172/2161-105X.1000424

Copyright: (C) 2017 Gosavi Rakhi A, et al. This is an open-access article distributed under the terms of the Creative Commons Attribution License, which permits unrestricted use, distribution, and reproduction in any medium, provided the original author and source are credited. 
Citation: Gosavi Rakhi A, Kapse Vijaykumar R, Mhaisekar Dilip G, Hashmi Syed F, Anandkumar Babulal L (2017) Indications, Outcome and Complications of Non-Invasive Positive Pressure Ventilation in Acute Respiratory Failure. J Pulm Respir Med 7: 424. doi: 10.4172/2161. 105X.1000424

Page 2 of 5

\section{Exclusion criteria}

- Age less than 13 years.

- Patients with altered consciousness and who were unable to control airway as NIPPV is contraindicated in those.

Relevant investigations (complete blood count, kidney and liver function tests, ECG, CXR, serum electrolytes, arterial blood gas analysis, microbiological investigations) were done in patients on mechanical ventilation in critical care unit.

\section{Criteria for acute respiratory failure}

At least two of the following criteria should be present:

- Respiratory distress with dyspnoea

- Use of accessory muscles of respiration

- Abdominal paradox

- Respiratory rate $>25 / \mathrm{min}$

\section{Acute exacerbation of chronic obstructive pulmonary disease}

- Fatigue, hypersomnolence, dyspnoea

- Oxygen saturation $<88 \%$ for $>10 \%$ of monitoring time despite $\mathrm{O}_{2}$ supplementation.

\section{Criteria for patients to put on non-invasive ventilation}

- Patient able to cooperate, can control airway and secretions, with adequate cough reflex, able to co-ordinate breathing with ventilator, haemodynamically stable, Blood $\mathrm{pH}>7.1$ and $\mathrm{PaCO}_{2}<92 \mathrm{mmHg}$, improvement in gas exchange, heart rate and respiratory rate within first two hours and normal functioning gastrointestinal tract.

All the patients included in the study were interviewed for demographic data and detail history of their illness. All selected patients were subjected to detail physical examination. NIV-BIPAP (mode spontaneous-timed) was used in all patients.

The patients were simultaneously started on standard medical treatment and $\mathrm{SpO}_{2}$ and arterial blood gases measured and noninvasive ventilation initiated with monitoring of pulse rate, respiratory rate, blood pressure and pulse oximetry. Arterial blood gases were measured at 1 hour and 4 hour after initiation of the non-invasive ventilation therapy.

Patients were also instructed about the procedure in detail prior to the application of NIV and were also positioned in a proper way.

\section{Protocol used for initiation and titrate bilevel positive airway pressure [11]}

NIPPV was delivered to patients in bed at an angle of $>30^{\circ}$ and in all patients a full face mask was used as an interface for delivery of positive pressure. Selected ventilator-Philips/Res-Med. and Set mode: spontaneous-timed. Started the IPAP at $8 \mathrm{~cm} \mathrm{H}_{2} \mathrm{O}$ and the EPAP at $4 \mathrm{~cm} \mathrm{H}_{2} \mathrm{O}$. IPAP maximum time 0.15 to $0.25 \mathrm{sec}$ longer than the patient's actual inspiratory time was set. IPAP maximum time should not be set longer than $50 \%$ of the respiratory cycle. Headgear applied avoiding excessive strap tension (one or two fingers under strap); encouraged patient to hold mask. Connected interface to ventilator tubing and turned on ventilator. Started with low pressures/volumes in spontaneously triggered mode with backup rate; pressure-limited: 8 to $12 \mathrm{~cm} \mathrm{H}_{2} \mathrm{O}$ inspiratory; 3 to $5 \mathrm{~cm} \mathrm{H}_{2} \mathrm{O}$ expiratory. Volume-limited: 10 $\mathrm{ml} / \mathrm{kg}$. Gradually increased inspiratory pressure with 1 to $2 \mathrm{~cm} \mathrm{H}_{2} \mathrm{O}$ increments (10 to $20 \mathrm{~cm} \mathrm{H} O$ ) or tidal volume (10 to $15 \mathrm{ml} / \mathrm{kg}$ ) as tolerated to achieve alleviation of dyspnea, decreased respiratory rate, increased tidal volume (if being monitored), to provide more ventilator assistance and good patient-ventilator synchrony. Also increased EPAP in 1 to $2 \mathrm{~cm} \mathrm{H}_{2} \mathrm{O}$ increments to improve oxygenation or to relieve upper airway obstruction. If poor synchronization occurred, checked for leaks or altered IPAP maximum time to improve synchronization. Supplemental oxygen was used if baseline saturation remains low $\left(\mathrm{SpO}_{2}<85 \%\right.$ with finger pulse oximeter) with appropriate IPAP and EPAP settings. Readjusted straps as needed. IPAP or EPAP level was not increased beyond patient tolerance. Humidifier was added as indicated. In agitated patients mild sedation with intravenous lorazepam $0.5 \mathrm{mg}$ was used. Monitored blood gases (within 1 to $2 \mathrm{~h}$ and then as needed). Also patient is regularly evaluated clinically and investigated as per requirement. Bronchodilators and corticosteroids as nebulisers and antibiotic agents were given where clinically indicated.

Instituted alternative management plan if $\mathrm{PaCO}_{2}$ and $\mathrm{pH}$ have deteriorated after 1-2 $\mathrm{h}$ of NIV on optimal settings. If no improvement, continued with NIV and reassess with repeat arterial blood gas analysis after 4-6 hours. If still no improvement in $\mathrm{PaCO}_{2}$ and $\mathrm{pH}$ by 4-6 $\mathrm{h}$, alternative management plan was considered.

NIPPV failure was defined as the need for invasive mechanical ventilation (IMV) due to worsening of clinical features such as respiratory distress (tachypnea, tachycardia, increased work of breathing) hypotension, worsening of the level of consciousness, or laboratory evidence of worsening or persistent respiratory distress while on NIPPV.

Any deterioration of $\mathrm{pH}$ and increase $\mathrm{PaCO}_{2}$, worsening of mental status, intolerance to NIV (clinical and/or laboratory evidence of deterioration at any point during NIPPV intervention), such patients were proceeded to invasive ventilation within 4 hours of starting the therapy.

Arterial blood gas analysis was done at the time of weaning and 6 hours after weaning were done. Once the patient improved clinically and corroborated by improvements in arterial blood gases, weaning was initiated. During the weaning phase, the IPAP was decreased in gradations of $2-3 \mathrm{~cm}$ until the IPAP was $7-10 \mathrm{~cm}$. The application was then switched over to intermittent use. The time of weaning, thus, was different for each patient.

\section{NIPPV for weaning from invasive mechanical ventilation [12]}

If the patient of acute respiratory failure was intubated on the basis of clinical and laboratory deterioration the weaning criteria as following were evaluated:

- Improved underlying illness.

- Respiratory function:

- Respiratory rate $<35$ breaths/minute

- $\mathrm{FiO}_{2}<0.4, \mathrm{SaO}_{2}>90 \%, \mathrm{PEEP}<10 \mathrm{~cm} \mathrm{H}_{2} \mathrm{O}$

- Tidal volume $>5 \mathrm{ml} / \mathrm{kg}$

- Vital capacity $>10 \mathrm{ml} / \mathrm{kg}$

- Minute volume $<10 \mathrm{ml} / \mathrm{min}$

- Gas exchange stability $\left(\mathrm{PaO}_{2} \geq 60 \mathrm{mmHg}\right.$ with $\mathrm{SaO}_{2} \geq 90 \%$ and $\mathrm{FiO}_{2} \leq 40 \%$ ),

- Pulmonary mechanics stability (control of pulmonary edema, atelectasis, secretions and bronchospasm). 
Citation: Gosavi Rakhi A, Kapse Vijaykumar R, Mhaisekar Dilip G, Hashmi Syed F, Anandkumar Babulal L (2017) Indications, Outcome and Complications of Non-Invasive Positive Pressure Ventilation in Acute Respiratory Failure. J Pulm Respir Med 7: 424. doi: 10.4172/2161105X.1000424

Page 3 of 5

Absence of infection or fever.

Cardiovascular stability (like hemoglobin $\geq 8 \mathrm{~g} / \mathrm{dl}$, no severe arrhythmia), optimal fluid balance and electrolyte replacement.

Hemodynamic stability (absence of vasopressors or vasopressors in doses $\leq 5 \mu \mathrm{g} / \mathrm{kg} / \mathrm{min})$

Neurologic stability (Glasgow coma scale $>10$ ).

Prior to trial of weaning, there should be no residual neuromuscular blockade and sedation should be minimised so that cooperative and in a semi-recumbent position.

\section{Weaning failure}

Weaning failure is defined as the failure to pass a spontaneousbreathing trial or the need to reintubation within 48 hours following extubation. For studying NIPPV as a weaning method-1) included adults, with respiratory failure, invasively ventilated for at least 24 hours; 2) Immediate application of NPPV (BiPAP) after extubation. Patients with contraindications to NPPV were excluded. Patients needing intubation after extubation i.e. weaning failure or extubation failure patients were applied with NIPPV- BiPAP.

In present study effectiveness of NIV means improvement in ABG parameter and non-effectiveness means worsening of ABG parameter. All the study patients were followed up until discharge. Patients taking discharge against medical advice were excluded.

Collected data with the help of proforma was entered in MS EXCEL 2007 spread sheet and then analysed by SPSS 19 version software by Mann-Whitney U Test, the level of significance was 95\% C.I $(\alpha=0.05)$ and Power of the study (ß) was taken as 0.80 .

\section{Results}

Of the total 110 patients in study, there were 68 (61.81\%) male and $42(38.18 \%)$ female patients with the mean age of study population $49.40( \pm 9.89)$ years. Majority $48(43.63 \%)$ of the patients were in the age group of 55-74 years. The commonest indication of NIPPV in present study was COPD in $37(33.63 \%)$ cases followed by post extubation 30 (27.27\%), asthma $14(12.72 \%)$, ARDS $9(8.18 \%)$ and pneumonia 10 (9.09\%) (Tables 1-4).

Out of 110 patients taken on NIPPV, 18 (16.36\%) patients required ventilation for $<12 \mathrm{~h}, 30(27.27 \%)$ patients required for $12-24 \mathrm{~h}, 44$ (40\%) patients required for $24-48 \mathrm{~h}$. Prolonged mechanical ventilation

\begin{tabular}{|c|c|}
\hline Diseases & No. of patients (\%) \\
\hline COPD & $37(33.63 \%)$ \\
\hline Post-extubation & $30(27.27 \%)$ \\
\hline Asthma & $14(12.72 \%)$ \\
\hline Pneumonia & $10(9.09 \%)$ \\
\hline ARDS & $09(8.18 \%)$ \\
\hline Pulmonary edema & $06(5.45 \%)$ \\
\hline Bronchiectasis & $03(2.72 \%)$ \\
\hline ILD & $01(0.90 \%)$ \\
\hline Total & $110(100 \%)$ \\
\hline
\end{tabular}

Table 1: Indications for NIPPV.

\begin{tabular}{|c|c|c|}
\hline Outcome & Number of patients & Percentage (\%) \\
\hline Effective & 88 & $80 \%$ \\
\hline Non Effective & 22 & $20 \%$ \\
\hline Total & 110 & $100 \%$ \\
\hline
\end{tabular}

Table 2: Outcome of nippv in present study.

\begin{tabular}{|c|c|c|}
\hline Diseases & $\begin{array}{c}\text { Total cases on } \\
\text { NIPPV }\end{array}$ & $\begin{array}{c}\text { No. of cases Required Invasive } \\
\text { Ventilation }\end{array}$ \\
\hline COPD & 37 & $06(16.21 \%)$ \\
\hline Asthma & 14 & $01(7.14 \%)$ \\
\hline Bronchiectasis & 03 & $00(0 \%)$ \\
\hline ARDS & 09 & $05(55.55 \%)$ \\
\hline Pneumonia & 10 & $02(20 \%)$ \\
\hline Pulmonary edema & 06 & $02(33.33 \%)$ \\
\hline ILD & 01 & $00(0 \%)$ \\
\hline Post-extubation & 30 & $06(20 \%)$ \\
\hline Others & 00 & $00(0 \%)$ \\
\hline Total & 110 & $22(20 \%)$ \\
\hline
\end{tabular}

Table 3: Disease-wise distribution of patients and their outcome on NIPPV.

\begin{tabular}{|c|c|c|}
\hline Complications & No. of Cases $\mathbf{( n = 1 1 0 )}$ & Percentage (\%) \\
\hline Dry Mouth & 60 & $54.54 \%$ \\
\hline Facial Injury & 21 & $19.09 \%$ \\
\hline Aerophagia & 12 & $10.90 \%$ \\
\hline Ciaustrophobia & 5 & $4.54 \%$ \\
\hline Retained Secretions & 8 & $7.27 \%$ \\
\hline
\end{tabular}

Table 4: Complications of NIPPV ventilator in present study.

$(>48 \mathrm{~h})$ were required in $18(16.36 \%)$ patients. NIPPV was effective in $88(80 \%)$ but found non-effective in $22(20 \%)$.

(Mann-Whitney U Test was used, Z-Score=-7.22982. The $\mathrm{p}$-value is $<0.00001$. The result is significant at $\mathrm{p}<0.05)$.

Amongst the total 110 patients, 22 (20\%) patients required invasive ventilation, out of them 6 (16.21\%) of Chronic Obstructive Pulmonary Disease (COPD), 1 (7.14\%) of asthma, 5 (55.55\%) of ARDS, 2 (20\%) of pneumonia, $2(33.33 \%)$ of pulmonary edema, $6(20 \%)$ of post extubation patients. Out of 3 patients of bronchiectasis and 1 patient of ILD no one required invasive ventilation. This observed difference is statistically significant as Z-Score $=-7.22982$. The $\mathrm{p}$-value is $<0.00001$. The result is significant at $\mathrm{p}<0.05$. Calculated by Mann-Whitney $U$ Test and Power of the test is 0.80

A total of $39(81.25 \%)$ of hypercapnic respiratory failure patients, 27 $(75 \%)$ of hypoxic respiratory failure patients and $22(84.61 \%)$ of mixed respiratory failure patients weaned off successfully.

Noninvasive Ventilator was not effective $4(20 \%)$ were in the age group of $14-34$ years, 5 (16.66\%) in $35-54$ years, $11(22.91 \%)$ in $55-74$ years and $2(100 \%)$ were in the age group of $>75$ years.

Amongst the total 110 patients on NIPPV, dry mouth occurred in $60(54.54 \%)$ patient, facial injury occurred in $21(19.09 \%)$ patients, aerophagia in $12(10.90 \%)$ patients, claustrophobia observed in 5 $(4.54 \%)$ patients and retained secretions in $8(7.27 \%)$ patients.

\section{Discussion}

This prospective observational study was conducted to determine the indications, complications and outcome of non-invasive mechanical ventilation in patients of respiratory failure admitted in critical care unit due to various conditions.

In present study, the commonest indication for initiation of NIPPV was COPD 37 (33.63\%) followed by post-extubation 30 $(27.27 \%)$ in present study. Other indications were asthma $14(12.72 \%)$, bronchiectasis $3(2.72 \%)$, ARDS 9 (8.18\%), pneumonia 10 (9.09\%), pulmonary edema 6 (5.45\%), and ILD 1 (0.90\%). This was similar to Chawla, Rai and Agrawal [13-15] COPD was the commonest indication as $71.4 \%, 64.4 \%$ and $38.1 \%$ patients had COPD respectively. 
Citation: Gosavi Rakhi A, Kapse Vijaykumar R, Mhaisekar Dilip G, Hashmi Syed F, Anandkumar Babulal L (2017) Indications, Outcome and Complications of Non-Invasive Positive Pressure Ventilation in Acute Respiratory Failure. J Pulm Respir Med 7: 424. doi: 10.4172/2161105X.1000424

Page 4 of 5

In a present study, amongst the total 110 patients, NIPPV was effective in $88(80 \%)$ and noneffective in $22(20 \%)$ and this was statistically significant also as $\mathrm{Z}$-Score $=-7.22982$. The p-value is $<0.00001$. The result is significant at $\mathrm{p}<0.05$. Calculated by MannWhitney U Test. Similar to study done by George et al. [16] with success rate of NIPPV was $85 \%$ and Meduri et al. [17] with $80 \%$ success rate.

The main advantage of NIPPV is avoidance of intubation and therefore does not interfere with the performance of the upper airway including eating, talking and discharge of airway secretions. Evidence collected over the past decade shows that in acute respiratory failure secondary to COPD, application of NIPPV reduces mortality and length of hospital stay. In addition incidence of ventilator-associated pneumonia, nosocomial infections such as sepsis, sinusitis decreases due to shortening of hospital stay [18-24]. Efficiency of NIPPV in the treatment of respiratory failure secondary to chronic obstructive pulmonary disease (COPD) has been shown in many published studies [25-29]. A systematic review of randomized controlled trials that compared NIPPV plus usual medical care versus medical care alone in the treatment of respiratory failure secondary to COPD exacerbation demonstrated fewer complications and shorter duration of hospital stay [30]. The results of another systematic review of 14 studies in treatment of respiratory failure due to COPD exacerbations revealed that NIPPV decreases mortality, needs for intubation, rate of treatment failure, and thus provides rapid improvement of $\mathrm{PH}, \mathrm{PaCO}_{2}$, respiratory rate and decreases duration of hospital stay [31]. The available data from published studies indicate benefit of NIPPV in respiratory failure due to COPD exacerbation and so is recommended at earlier stage of respiratory failure prior to development of severe acidosis. In one study, application of NIPPV in acute respiratory failure, reduced intubation and mechanical ventilation in $20 \%$ of patients [32].

The failure rates of NIPPV can range from $5 \%$ to $50 \%$ in different studies depending on the etiology and severity of ARF [7-10]. The success rate of NIPPV was $87.5 \%$ for ARF due to COPD and $61.5 \%$ for ARF due to other causes which are similar to reintubation rates described elsewhere both from India $[16,18]$ and the EuropeanAmerican countries [10,19].

In the present study, amongst the total 110 patients $22(20 \%)$ patients required invasive ventilation, out of them $6(16.21 \%)$ of COPD, 1 (7.14\%) of asthma, 5 (55.55\%) of ARDS, 2 (20\%) of pneumonia, 2 (33.33\%) of pulmonary edema, 6 (20\%) of post extubation patients. Out of 3 patients of bronchiectasis and 1 patient of ILD no one required invasive ventilation. Phua J et al. [10] reported that risk of NIV failure was lower in COPD than in other condition (19\% vs. $47 \%)$ respectively. In a study done by Schettino et al. [20], intubation rate was $18 \%$, $24 \%, 38 \%, 40 \%$ and $60 \%$, respectively, for patients with cardiogenic pulmonary edema, acute exacerbation of COPD, acute hypercapnic respiratory failure, post extubation respiratory failure patients and acute hypoxemic respiratory failure.

In the present study, amongst the total 110 patients $22(20 \%)$ patients required invasive ventilator, out of them 12 (54.54\%) were due to worsening of ABG parameter, 8 (36.36\%) were due to altered consciousness, and $2(9.09 \%)$ were due to increase respiratory secretions. Phua et al. [10] found that NIV was more effective in preventing endotracheal intubation in hypercapnic ARF due to COPD than non-COPD conditions. In the study by Yoshida et al. [21] studied a total of 47 patients with ALI who received NIV, and 33 patients (70\%) successfully avoided endotracheal intubation.

In the present study, 39 (81.25\%) of hypercapnic respiratory failure patients weaned off successfully, 27 (75\%) of Hypoxic respiratory failure patients weaned off successfully and 22 (84.61\%) of Mixed respiratory failure patients weaned off successfully. Wysocki et al. [22] found that intermittent positive support ventilation delivered from a ventilator through a face mask (NIPSV) reduced the need for endotracheal intubation with a success rate of $47 \%$ in patients presenting with acute respiratory failure from various etiologies.

Amongst the total 110 patients on NIV, in 30 patients NIPPV used for weaning after early extubation $6(20 \%)$ of them required reintubation, total 19 patients were of Poisoning out of them 3 (15.7\%) required reintubation, 4 of COPD $2(50 \%)$ required reintubation, 2 patient of ARDS was given NIPPV support after early extubation 1 (50\%) required reintubation. Girault et al. [23] found that it is possible to use NIV immediately as an early extubation and weaning technique in intubated (ACRF) acute-on-chronic respiratory failure patients who are difficult to wean, 13 of 17 (76.5\%) in the NIV group were successfully weaned and extubated.

In present study, NIV was not effective 11 (22.91\%) patients of 55-74 years. Patients with worsening of ABG parameter 12 (54.54\%) followed by a poor level of consciousness 8 (36.36\%) were associated with a poor response to NIPPV, ultimately requiring intubation. In a study done by Antonelli et al. [19], of the eligible 354 patients NIV failed in $30 \%(108 / 354)$ patients.

NIV aims to eliminate the complications of invasive MV, such as ventilator-associated pneumonia (VAP) and barotrauma. VAP rates are high in patients put on $\mathrm{MV}$, with $8-28 \%$ of patients developing this problem [24].

In the present study, common complications observed were dry mouth in $60(54.54 \%)$ patients, facial injury in 21 (19.09\%) patients and claustrophobia in $5(4.54 \%)$ patients. None of the patient in our study revealed a new infiltration on the X-ray associated with fever, tachypnea, or leucocytosis that could suggest nosocomial pneumonia. Mehta and Hill found complications such as nasal/oral dryness (10$20 \%$ ), facial skin erythema (20-34\%), claustrophobia (5-10\%) and major complications such as aspiration pneumonia $<5 \%$, hypotension $<5 \%$ and pneumothorax $<5 \%[11]$.

The results of this study show that NIPPV can be utilized as an effective modality in the management of ARF due to diverse etiologies. NIPPV was associated with a reduced need for invasive mechanical ventilation and significant outcome and minor complications.

\section{Acknowledgment}

We would like to thank the patients, nursing and medical staffs of the study hospital for their cooperation for the success of the study.

\section{References}

1. Brochard L, Mancebo J, Wysocki M, Lofaso F, Conti G, et al. (1995) Noninvasive ventilation for acute exacerbation of chronic obstructive pulmonary disease. N Engl J Med 333: 817-822.

2. Plant PK, Owen JL, Elliott MW (2000) Early use of non-invasive ventilation for acute exacerbations of chronic obstructive pulmonary disease on genera respiratory wards: A multicentre randomizes controlled trial. Lancet 355: 193195

3. Peter JV, Moran JL, Phillips-Hughes J, Graham P, Bersten AD (2006) Effect of non-invasive positive pressure ventilation (NIPPV) on mortality in patients with acute cardiogenic pulmonary oedema: A meta-analysis. Lancet 367: 11551163.

4. Keenan SP, Sinuff T, Cook DJ, Hill NS (2004) Does Non-invasive positive pressure ventilation improve outcome in acute hypoxemic respiratory failure? A systemic review. Crit Care Med 32: 2526.

5. Trevisan CE, Vieira SR (2008) Non-invasive mechanical ventilation may be 
Citation: Gosavi Rakhi A, Kapse Vijaykumar R, Mhaisekar Dilip G, Hashmi Syed F, Anandkumar Babulal L (2017) Indications, Outcome and Complications of Non-Invasive Positive Pressure Ventilation in Acute Respiratory Failure. J Pulm Respir Med 7: 424. doi: 10.4172/2161. 105X.1000424

Page 5 of 5

useful in treating patients who fail weaning from invasive mechanical ventilation: A randomized clinical trial. Crit Care 12: R51.

6. Ferrer M, Esquinas A, Arancibia F (2003) Non-invasive ventilation during persistent weaning failure: a randomized controlled trial. Am J Respir Crit Care Med 168: 70-76.

7. Plant PK, Owen JL, Elliott MW (2001) Non-invasive ventilation in acute exacerbations of chronic obstructive pulmonary disease: long term survival and predictors of in-hospital outcome. Thorax 56: 708-712.

8. Nava S, Ceriana $P$ (2004) Causes of failure of non-invasive mechanical ventilation. Respir Care 49: 295-303.

9. Confalonieri M, Garuti G, Cattaruzza MS, Osborn JF, Antonelli M, et al. (2005) Italian non-invasive positive pressure ventilation (NPPV) study group. A chart of failure risk for non-invasive ventilation in patients with COPD exacerbation. Eur Respir J 25: 348-355.

10. Phua J, Kong K, Lee KH, Shen L, Lim TK (2005) Non-invasive ventilation in hypercapnic acute respiratory failure due to chronic obstructive pulmonary disease vs. other conditions: Effectiveness and predictors of failure. Intensive Care Med 31: 533-539.

11. Mehta S, Hill NS (2001) Non-invasive ventilation. Am J Respir Crit Care Med 163: $540-577$.

12. Boles JM, Bion J, Connors A (2007) Weaning from mechanical ventilation. Eur Respir J 29: 1033-1056.

13. Chawla R, Sidhu US, Kumar V, Nagarkar S, Brochard L (2008) Non-invasive ventilation: A survey of practice patterns of its use in India. Indian J Crit Care Med 12: 4

14. Rai SP, Panda BN, Upadhyay KK (2004) Non-invasive positive pressure ventilation in patients with acute respiratory failure. Clin Chest Med 60: 224226.

15. Agarwal R, Handa A, Aggarwal AN, Gupta D, Behera D (2009) Outcomes of Non-invasive ventilation in acute hypoxemic respiratory failure in a respiratory intensive care unit in north India. Respiratory Care 54: 12

16. George IA, George J, John P, Peter JV, Christopher S (2007) An evaluation of the role of Non-invasive positive pressure ventilation in the management of acute respiratory failure in a developing country. Indian J Med Sci 61: 495-504.

17. Meduri GU, Turner RE, Abou-Shala N, Wunderink R, Tolley E (1996) Noninvasive positive pressure ventilation via face mask. Chest 109: 179-193.

18. Singh VK, Khanna P, Rao BK, Sharma SC, Gupta R (2006) Outcome predictors for non-invasive positive pressure ventilation in acute respiratory failure. $J$ Assoc Physicians India 54: 361-365.

19. Antonelli M, Conti G, Rocco M (2002) Non-invasive positive pressure ventilation vs. conventional oxygen supplementation in hypoxemic patients undergoing diagnostic bronchoscopy. Chest 121: 1149-1154.

20. Neila BA, Robert M (2008) Non-invasive positive-pressure ventilation in acute respiratory failure outside clinical trials: Experience at the massachusetts general hospital.

21. Yoshida Y, Takeda S, Akada S, Hongo T, Tanaka K, et al. (2008) Factors predicting successful Non-invasive ventilation in acute lung injury. J Anesth 22 201-216.

22. Wysocki M, Antonelli M (2001) Non-invasive mechanical ventilation in acute hypoxaemic respiratory failure. Eur Respir J 18: 209-220.

23. Girault C, Daudenthun I, Chevron V, Tamion F, Leroy J, et al. (1999) Noninvasive ventilation as a systematic extubation and weaning technique in acuteon-chronic respiratory failure: A prospective, randomized controlled study. Am J Respir Crit Care Med 160: 86-92.

24. Chastre J, Fagon JY (2002) Ventilator associated pneumonias. Am J Respi Crit Care Med 165: 867-903.

25. Hess DR (2005) Non-invasive positive-pressure ventilation and ventilator associated pneumonia. Respir Care 50: 924-929.

26. Antonelli M, Conti G, Rocco M (1998) A comparison of Non-invasive positivepressure ventilation and conventional mechanical ventilation in patients with acute respiratory failure. N Engl J Med 339: 429-435.

27. Vital FM, Ladeira MT, Atallah AN (2013) Non-invasive positive pressure ventilation (CPAP or bilevel NPPV) for cardiogenic pulmonary oedema. Cochrane Database Syst Rev 5: CD005351

28. Demoule A, Girou E, Richard JC, Taille S, Brochard L (2006) Benefits and risks of success or failure of Non-invasive ventilation. Intensive Care Med 32: 1756 1765.

29. Squadrone E, Frigerio P, Fogliati C (2004) Non-invasive vs. invasive ventilation in COPD patients with severe acute respiratory failure deemed to require ventilatory assistance. Intensive Care Med 30: 1303-1310.

30. Lightowler JV, Wedzicha JA, Elliott MW, Ram FS (2003) Non-invasive positive pressure ventilation to treat respiratory failure resulting from exacerbations of chronic obstructive pulmonary disease: Cochrane systematic review and metaanalysis. BMJ 326: 185.

31. Ram FS, Picot J, Lightowler J, Wedzicha JA (2004) Non-invasive positive pressure ventilation for treatment of respiratory failure due to exacerbations of chronic obstructive pulmonary disease. Cochrane Database Syst Rev 1 : CD004104.

32. Peter JV, Moran JL, Phillips-Hughes J, Warn D (2002) Non-invasive ventilation in acute respiratory failure--a meta-analysis update. Crit Care Med 30: 555-562. 